\section{The phosphatidylinositol cycle and the regulation of arachidonic acid production}

\author{
Eduardo G. Lapetina, M. M. Billah \& P. Cuatrecasas
}

Department of Molecular Biology, The Wellcome Research Laboratories, Research Triangle Park, North Carolina 27709, USA

An increase in the metabolism of phosphatidylinositol occurs in a wide variety of tissues by the action of specific ligands ${ }^{1-3}$. In platelets, the interaction of thrombin with its receptor initiates the degradation of phosphatidylinositol by the action of a specific phospholipase $C$ (refs 4-8). In normal conditions of stimulation, the resultant 1,2-diacylglycerol is rapidly and completely phosphorylated to phosphatidic acid ${ }^{4-11}$. The formation of phosphatidic acid precedes the release of arachidonic acid from the phospholipids of stimulated platelets ${ }^{5}$. This early appearence of phosphatidate might result in the initial production of arachidonic acid and lysophosphatidic acid by the action of a phospholipase $A_{2}$ specific for phosphatidate ${ }^{12}$. Phosphatidate/lysophosphatidate could induce calciumgating ${ }^{13-1 s}$ and subsequently stimulate phospholipases of the $\mathbf{A}_{2}$-type ${ }^{8}$, that degrade phosphatidylcholine, phosphatidylethanolamine and a further fraction of phosphatidylinositol ${ }^{6}$. Alternatively, the lysophosphatidate produced may serve as a substrate for the transfer of arachidonate directly from other phospholipids ${ }^{16,17}$ to form new phosphatidate which in turn can release more arachidonate. Overall, such a sequence would be equivalent to phospholipase $A_{2}$ activation of other phospholipids. Our present data indicate that when the release of arachidonic acid is completely inhibited by cyclic AMP or quinacrine, phosphatidic acid is redirected entirely to phosphatidylinositol and there is no production of arachidonate. In these conditions, the availability of calcium might be profoundly restricted. The correlation in platelets of a phosphatidylinositol by a specific phospholipase $A_{2}$ might suggest that these phenomena are applicable to activations in other cell systems.

Phosphatidylinositol is not the only phospholipid that contributes to the production of arachidonic acid in stimulated platelets ${ }^{4-10,18}$. Phosphatidylcholine and phosphatidylethanolamine also release arachidonic acid by the action of phospholipase $A_{2}$ activities ${ }^{8}$. Both lysophosphatidylcholine and lysophosphatidylethanolamine have recently been found in stimulated platelets ${ }^{10,18}$. In a similar way, lysophosphatidic acid is also produced in intact platelets that have been prelabelled with ${ }^{32} \mathrm{P}$ and stimulated with thrombin (Fig. 1). Thrombin is very effective in producing phosphatidic acid ${ }^{4-6.19}$ and lysophosphatidic acid $^{19}$, whereas ionophore A23187 forms virtually no phosphatidic acid ${ }^{4,5}$ or lysophosphatidic acid (Fig. 1). Calcium ions enhance the thrombin-induced formation of phosphatidic acid as well as of lysophosphatidic acid (Fig. 1). We have described elsewhere the existence of a specific phospholipase $A_{2}$ which is present in platelet membranes and which specifically degrades phosphatidic acid ${ }^{12}$. This enzyme activity $\left(K_{\mathrm{m}} 20 \mu \mathrm{M}\right)$ is most active at $p \mathrm{H} 7.0$, requires $\mathrm{Ca}^{2+}(10 \mu \mathrm{M})$ for maximal activity and is inhibited by quinacrine ${ }^{12}$. The existence and specific properties of this enzyme suggest a possible important role in the production of arachidonic acid in stimulated platelets. This phosphatidate-specific phospholipase $\mathbf{A}_{2}$ has distinctly different properties from those of the phospholipases $\mathrm{A}_{2}$ that degrade phosphatidylethanolamine and phosphatidylcholine $e^{8}$, as its activity does not depend on the presence of detergents, alkaline $p \mathrm{H}$ or high concentration of $\mathrm{Ca}^{2+}$.

Phosphatidate is a key intermediate in the phosphatidylinositol cycle ${ }^{1-3}$. In this cycle, four consecutive enzyme activities are involved in the degradation and resynthesis of phosphatidylinositol (phosphatidylinositol-specific phospholipase C; 1,2-diacylglycerol kinase; CTP-phosphatidate: cytidyl

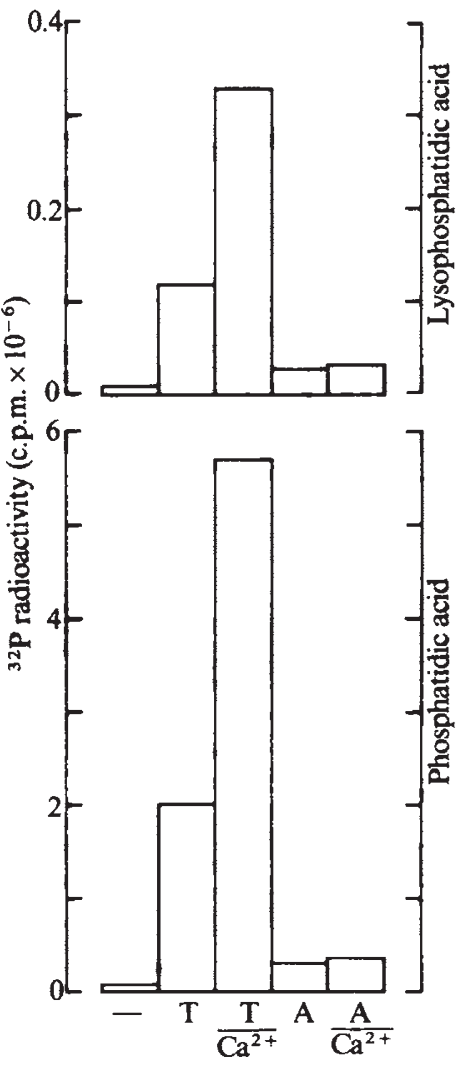

Fig. 1 Effect of thrombin and ionophore A23187 on the formation of phosphatidic acid and lyosphosphatidic acid in platelets. Horse platelets were labelled with ${ }^{32} \mathrm{P}$-orthophosphate after separation from one $(550 \mathrm{ml})$ unit of blood as described previously ${ }^{5,6}$. Platelets were then resuspended in $10 \mathrm{ml}$ of buffer $(134$ $\mathrm{mM} \mathrm{NaCl}, 15 \mathrm{mM}$ Tris-HCl $p \mathrm{H} \mathrm{7.4,1} \mathrm{mM}$ EGTA, $5 \mathrm{mM}$ glucose), $5 \mathrm{mCi}$ of ${ }^{32} \mathrm{P}$-orthophosphate were added and the platelets incubated at $37^{\circ} \mathrm{C}$ for $2 \mathrm{~h}$. After centrifugation and resuspension, the final concentration of platelets was $1 \times 10^{9}$ per $0.5 \mathrm{ml}$, which was the volume used for the assays. Samples $(0.5 \mathrm{ml})$ were incubated with thrombin $(\mathrm{T})\left(1\right.$ unit $\left.\mathrm{ml}^{-1}\right)$ or ionophore $\mathrm{A} 23187$ (A) $(1 \mu \mathrm{M}) \pm$ calcium chloride $(3 \mathrm{mM})$ in both cases, for $10 \mathrm{~min}$ at $37^{\circ} \mathrm{C}$. Lipid extraction and chromatographic separation of lipids have been detailed elsewhere ${ }^{5,6}$. Phosphatidic acid and lysophosphatidic acid were separated by a TLC method which uses oxalateimpregnated plates as described before ${ }^{12}$

transferase; CDP-1,2-diacylglycerol-inositol phosphatidyl transferase). To study the effects of calcium on the phosphatidic acid and phosphatidylinositol of stimulated platelets, platelets were labelled with ${ }^{32} \mathrm{P}$-orthophosphate and resuspended in an EGTA-containing buffer. If those platelets are then incubated with quinacrine and stimulated with thrombin, the release of arachidonic acid is completely blocked but phosphatidic acid is formed as a consequence of the degradation of phosphatidylinositol ${ }^{6}$. After an initial period, the label in phosphatidate decreases while the labelling of phosphatidylinositol increases (Fig. 2). This increased conversion of phosphatidate to phosphatidylinositol is blocked by the addition of ionophore A23187 plus calcium ions (Fig. 2). In this case, there is a further accumulation of labelled phosphatidic acid while the increased labelling of phosphatidylinositol is completely blocked (Fig. 2). These results indicate that calcium inhibits the resynthesis of phosphatidylinositol from phosphatidic acid after thrombin stimulation (Fig. 2$)^{10}$. In fact, $\mathrm{Ca}^{2+}$ has a direct inhibitory action on the enzymes involved in the resynthesis process (CTPphosphatidate: cytidyl transferase and CDP-1,2-diacylglycerolinositol phosphatidyl transferase $)^{20.21}$ These data indicate that the phosphatidylinositol cycle can actively function in the presence of quinacrine, which completely blocks the production of arachidonic acid from all platelet phospholipids ${ }^{6}$. Calcium, on the other hand, interrupts the phosphatidylinositol cycle and phosphatidate accumulates (Fig. 2). 
Cyclic AMP inhibits the 'release reaction' of platelets as well as aggregation ${ }^{4}$. The action of cyclic AMP on platelet enzymes has been variously ascribed to the inhibition of the conversion of arachidonic acid to cyclooxygenase metabolites ${ }^{22}$, the production of arachidonic acid from phospholipids ${ }^{4.23-27}$ and the formation of phosphatidic acid ${ }^{4,5}$. All these actions ultimately reduce the production of arachidonate or its conversion to active cyclooxygenase products. We previously described the action of cyclic AMP in reducing phosphatidic acid to an inhibition of phospholipase $C^{7}$. Further studies now reveal that the phosphatidylinositol cycle is not inhibited by cyclic AMP despite the profound reduction in the quantity of phosphatidate produced. Figure 3 describes the action of cyclic AMP on the reactions related to the increased turnover of phosphatidylinositol in platelets prelabelled with ${ }^{32} \mathrm{P}$-orthophosphate. Cyclic AMP seems substantially to increase the rate of conversion of phosphatidate to phosphatidylinositol, thereby decreasing the steady state concentration of phosphatidate. As we are proposing that the production of arachidonic acid might be related to the formation of phosphatidate, this could serve as the basis for the cyclic AMP-induced inhibition of arachidonate production. In the presence of quinacrine, which completely blocks the formation of arachidonic acid from various phospholipids ${ }^{6.12}$, thrombin greatly increases the breakdown and resynthesis (turnover) of phosphatidylinositol as shown by increased labelling of ${ }^{32} \mathrm{P}$ phosphatidylinositol (Fig. 3). These data indicate that the integrity of the phosphatidylinositol cycle is maintained in

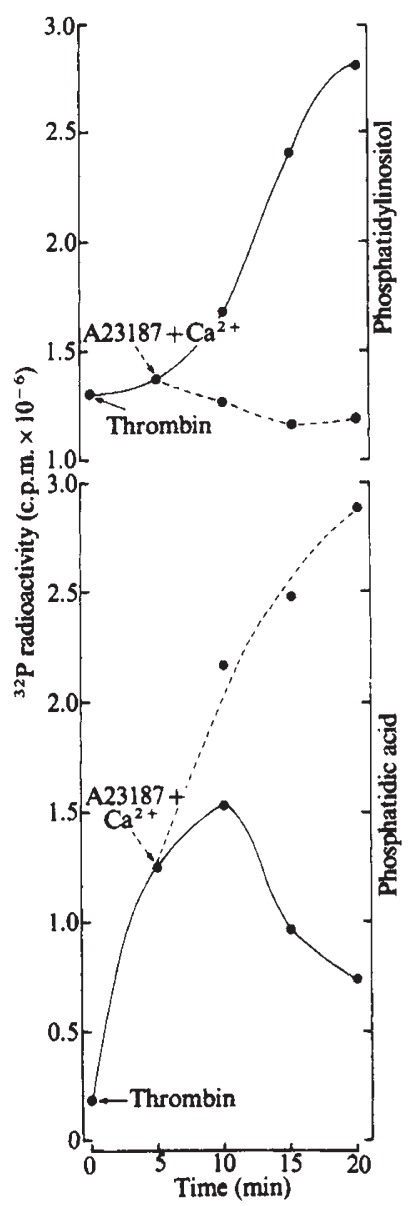

Fig. 2 Effect of ionophore A23187 plus calcium ions on phosphatidylinositol and phosphatidic acid of platelets pretreated with quinacrine and thrombin. Platelets prelabelled with ${ }^{32} \mathrm{P}$-orthophosphate were obtained as for Fig. 1 . Samples $(0.5 \mathrm{ml})$ were incubated with quinacrine for $5 \mathrm{~min}$ at $37^{\circ} \mathrm{C}$ and then thrombin (1 unit $\mathrm{ml}^{-1}$ ) was added for different periods of time as indicated. After 5 min treatment with thrombin, in some assays (----) ionophore A23187 $(1 \mu \mathrm{M})$ plus calcium chloride $(3 \mathrm{mM})$ were added. Other details as for Fig 1.
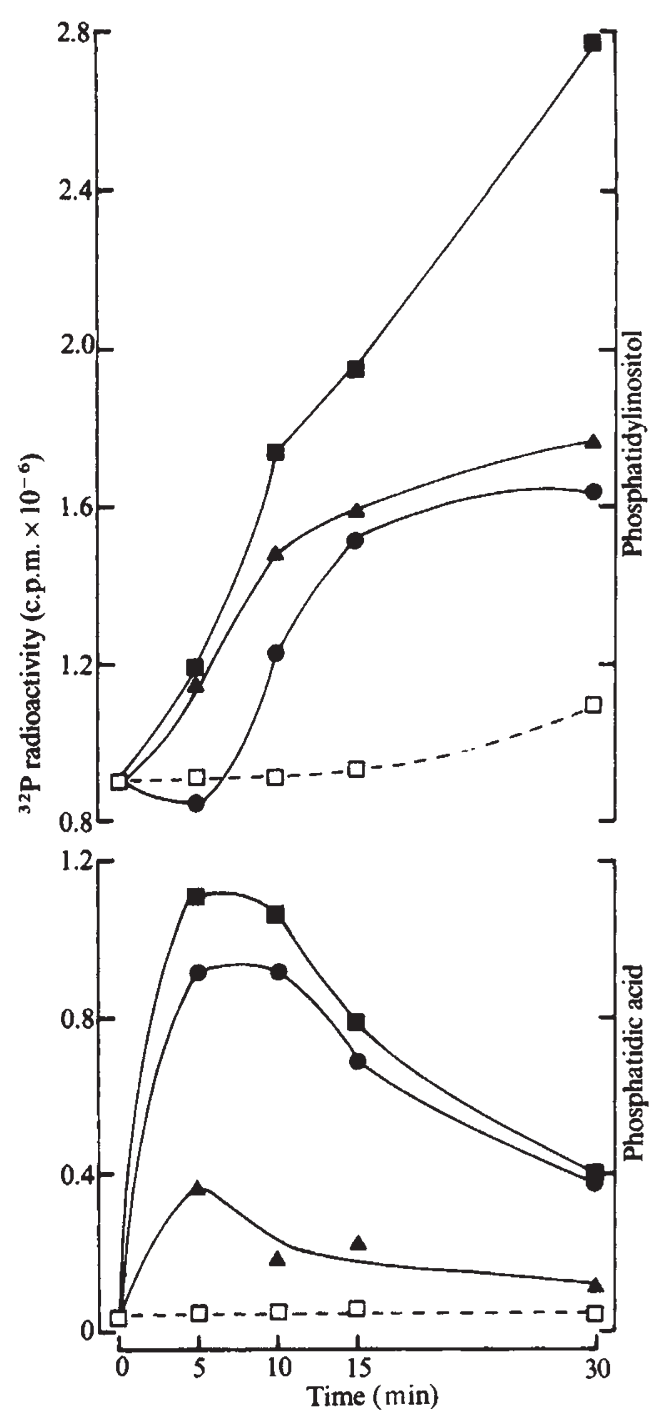

Fig. 3 Effect of thrombin on phosphatidylinositol and phosphatidic acid of platelets pretreated with cyclic AMP or quinacrine. Preincubations with quinacrine $(0.75 \mathrm{mM})$ ( $\mathrm{C}$ ) or dibutyryl cyclic AMP ( $1 \mathrm{mM}$ ) (A) were for $5 \mathrm{~min}$ and thrombin ( 1 unit $\mathrm{ml}^{-1}$ ) was then added for different periods of time as indicated. Assays containing only thrombin; $\square$, control assays. Phosphatidic acid was separated on TLC ${ }^{5}$ and phosphatidylinositol was separated on formaldehyde-impregnated paper ${ }^{5,6}$. Other details as for Fig 1.

conditions (cyclic AMP or quinacrine) in which the specific release of arachidonic acid induced by thrombin is completely blocked.

The information presented here indicates that calcium interrupts the phosphatidylinositol $\mathrm{cycle}^{1-3}$ and leads to accumulation of the intermediate product, phosphatidic acid. In stimulated platelets a specific phospholipase $\mathrm{A}_{2}$ released arachidonic acid from the phosphatidate produced ${ }^{12}$, with the consequent appearence of lysophosphatidic acid. This phosphatidate-lysophosphatidate interconversion might be important in the subsequent and specific mobilization of arachidonic acid from phosphatidylcholine, phosphatidylethanolamine and phosphatidylinositol ${ }^{6}$. In thrombinstimulated platelets cyclic AMP enhances the overall turnover of the phosphatidylinositol cycle by increasing the rate of conversion of phosphatidic acid to phosphatidylinositol, and thus inhibits the release of arachidonic acid from various phospholipids.

Received 16 February; accepted 22 May 1981.

1. Lapetina, E. G. \& Michelt, R. H. FEBS Lett. 31, 1-10 (1973).

2. Michell, R. H. Biochim. biophys. Acta 415, 81-147 (1975).

2. Michell, R. H. Biochim. biophys. Acta $415,81-147(1975)$

3. Michell, R. H. Trends biochem. Sci 4, 128-131 (1979).
4. Lapetina, E. G., Chandrabose, K. \& Cuatrecasas, P. Proc. natn. Acad. Sci. U.S.A. 75, 818-822 (1978). 
5. Lapetina, E. G. \& Cuatrecasas, P. Biochim. biophys. Acta 573, 394-402 (1979).

6. Lapetina, E. G., Billah, M. M. \& Cuatrecasas, P. J. biol. Chem 256, 5037-5040 (1981).

7. Billah, M. M., Lapetina, E. G. \& Cuatrecasas, P. Biochem. biophys. Res. Commun. 90, 92-98 (1979).

8. Billah, M. M., Lapetina, E. G. \& Cuatrecasas, P. J. biol. Chem. 255, 10227 10231 (1980).

9. Walenga, R., Vanderhoek, J. Y. \& Feinstein, M. B. J. biol. Chem. 255, 6024-6027 (1980).

10. Broekman, M. J., Ward, M. W. \& Marcus, A. J. J. clin. Invest. 66, 275-283 (1980).

11. Lapetina, E. G., Billah, M. M. \& Cuatrecasas, P. in The Regulation of Coagulation (eds Mann, K. G. \& Taylor, F. B.) 491-497 (Elsevier, New York, 1980)

12. Billah, M. M., Lapetina, E. G. \& Cuatrecasas, P. J. biol. Chem. 256, 5399-5403 (1981).

13. Gerrard, J. M., Butler, A. M., Peterson, D. A. \& White, J. G. Prostaglandins Med. 1, 387-396 (1978).

14. Gerrard, J. M. et al. Am. J. Path. 96, 423-438 (1979).

15. Gerrard, J. M., Kindom, S. E., Peterson, D. A. \& White, J. G. Am. J. Path. 97, 531-548 (1979).

16. Bereziat, G., Chambaz, J., Trugman, G., Pepin, D. \& Polonovski, J. J. Lipid Res. 19. 495-500 (1978).

17. Irvine, R. F. \& Dawson, R. M. C. Biochem. biophys. Res. Commun. 91, 1399-1405 (1979).

18. McKean, M. L., Smith, J. B. \& Silver, M. J. J. biol. Chem. 256, 1522-1524 (1981).

19. Mauco, G., Chap, H., Simon, M. F. \& Douste-Blazy, L. Biochemie 60, 653-661 (1978),

20. Agranoff, B. W., Gradley, R. M. \& Grady, R. O. J. biol. Chem. 233, 1077-1083 (1958).

21. Bleasdale, J. E., Wallis, P., MacDonald, P. C. \& Johnston, J. M. Biochim. biophys. Acta 575, $135-147$ (1979).

22. Malmsten, C., Granstrom, E. \& Samuelsson, B. Biochem. biophys. Res. Commun. 68, 569-576 (1976).

23. Lapetina, E. G., Schmitges, C. J., Chandrabose, K. \& Cuatrecasas, P. Biochem. biophys, Res. Commun. 76, 828-835 (1977).

24. Lapetina, E. G., Schmitges, C. J., Chandrabose, K. \& Cuatrecasas, P. in Advances in Prostaglandin and Thromboxane Research Vol. 3 (eds Galli, C., Galli, G. \& Porcellati, G.) 127-135 (Raven, New York, 1978).

25. Minkes, M. et al. J. clin. Invest. 59, 449-454 (1977).

26. Gerrard, J. M., Peller, J. D., Krick, T. P. \& White, J. G. Prostaglandins 14, 39-50 (1977).

27. Feinstein, M. B., Becker, E. L. \& Frazer, C. Prostaglandins 14, 1075-1093 (1977).

\section{4',6-Dichloroflavan (BW683C), a new anti-rhinovirus compound}

\author{
D. J. Bauer, J. W. T. Selway*, J. F. Batchelor, \\ Margaret Tisdale, Ian C. Caldwell \& D. A. B. Young
}

Wellcome Research Laboratories, Langley Court, Beckenham, Kent BR3 3BS, UK

Derivatives of flavan have been synthesized as chemical intermediates, but the only reported biological action is the ability of certain alkyl and alkoxy derivatives to lower blood cholesterol concentrations ${ }^{1}$. It was therefore surprising to discover that flavan itself (Table 1) is a highly effective inhibitor of the replication of certain serotypes of rhinovirus, and that a simple derivative, BW683C (4',6-dichloroflavan), is the most potent antiviral compound yet reported. The present work examines the antiviral activity of flavan derivatives with a view to selecting the compound most suitable for trial in volunteers infected with a common cold virus.

4',6-Dichloroflavan, which is new to the chemical literature, has been prepared by methods used for the synthesis of substituted flavans $\mathrm{s}^{2-5}$. It is a colourless crystalline solid, m.p. $101^{\circ} \mathrm{C}$, soluble in water only to the extent of $1 \mathrm{mg} \mathrm{l}^{-1}$ at room temperature.

Antiviral activity was detected in vitro by means of plaque inhibition tests ${ }^{6,7}$ with monolayers of M-HeLa cells ${ }^{8,9}$ infected with rhinovirus 1B. Activity was measured by plaque reduction assays in which doubling concentrations of compound were incorporated into the overlay medium. Plaque counts, expressed as a percentage of the control value, were plotted against the logarithm of the compound concentration, to yield a doseresponse line from which the $\mathrm{IC}_{50}$ value could be determined. The $\mathrm{IC}_{50}$ values for $\mathrm{BW} 683 \mathrm{C}$ and several analogues are shown in Table 1. Flavan $\left(R_{6}=R_{4^{\prime}}=H\right)$, with an $I_{50}$ of $0.046 \mu \mathrm{M}$, is one of the least active of the compounds tested. The activity is generally increased by the presence of a single halogen substituent, and more so by the presence of two chlorine atoms, with the most active compound tested being BW683C which, with an $\mathrm{IC}_{50}$ of $0.007 \mu \mathrm{M}$, is some six times more potent than the parent compound. The $\mathrm{IC}_{90}$ of $\mathrm{BW} 683 \mathrm{C}$ was $0.02 \mu \mathrm{M}$.
Table 1 Structure-activity relationship of a selection of halogensubstituted flavans against rhinovirus type 1B<smiles>[R6]c1ccc(C2CCc3cc([R6])ccc3O2)cc1</smiles>

\begin{tabular}{llc}
\hline $\mathrm{R}_{6}$ & $\mathrm{R}_{4}^{\prime}$ & $\mathrm{IC}_{50}(\mu \mathrm{M})$ \\
$\mathrm{H}$ & $\mathrm{H}$ & 0.046 \\
$\mathrm{~F}$ & $\mathrm{H}$ & 0.020 \\
$\mathrm{Cl}$ & $\mathrm{H}$ & 0.050 \\
$\mathrm{Br}$ & $\mathrm{H}$ & 0.019 \\
$\mathrm{H}$ & $\mathrm{F}$ & 0.018 \\
$\mathrm{H}$ & $\mathrm{Cl}$ & 0.039 \\
$\mathrm{H}$ & $\mathrm{Br}$ & 0.036 \\
$\mathrm{~F}$ & $\mathrm{~F}$ & 0.068 \\
$\mathrm{Cl}$ & $\mathrm{Cl}$ & 0.007 \\
$\mathrm{Br}$ & $\mathrm{Br}$ & 0.010 \\
$\mathrm{I}$ & $\mathrm{I}$ & 0.043 \\
\hline
\end{tabular}

For any agent to be effective in the prophylaxis or treatment of the common cold, it must be active against a high proportion of rhinovirus serotypes. There are at least 89 serotypes, the most prevalent being $1 \mathrm{~A}, 1 \mathrm{~B}, 2,4,15,29,30$ and 31 (ref. 10). $\mathrm{IC}_{50}$ values were obtained for BW683C against 19 serotypes (Table 2). Seven of the eight most prevalent serotypes were inhibited, although they varied considerably in sensitivity. The sensitivity of the other 11 serotypes was also variable, but was sufficient to suggest that the compound may be clinically useful.

In tissue culture tests $4^{\prime}, 6$-dichloroflavan did not inhibit the replication of other RNA viruses, including bunyavirus, coronavirus, equine rhinovirus, influenza virus (NWS strain), measles virus, poliovirus (Sabin 1), Semliki Forest virus, Sindbis virus and respiratory syncytial virus. It also failed to inhibit the DNA viruses adenovirus type 5 and herpesvirus type 1.

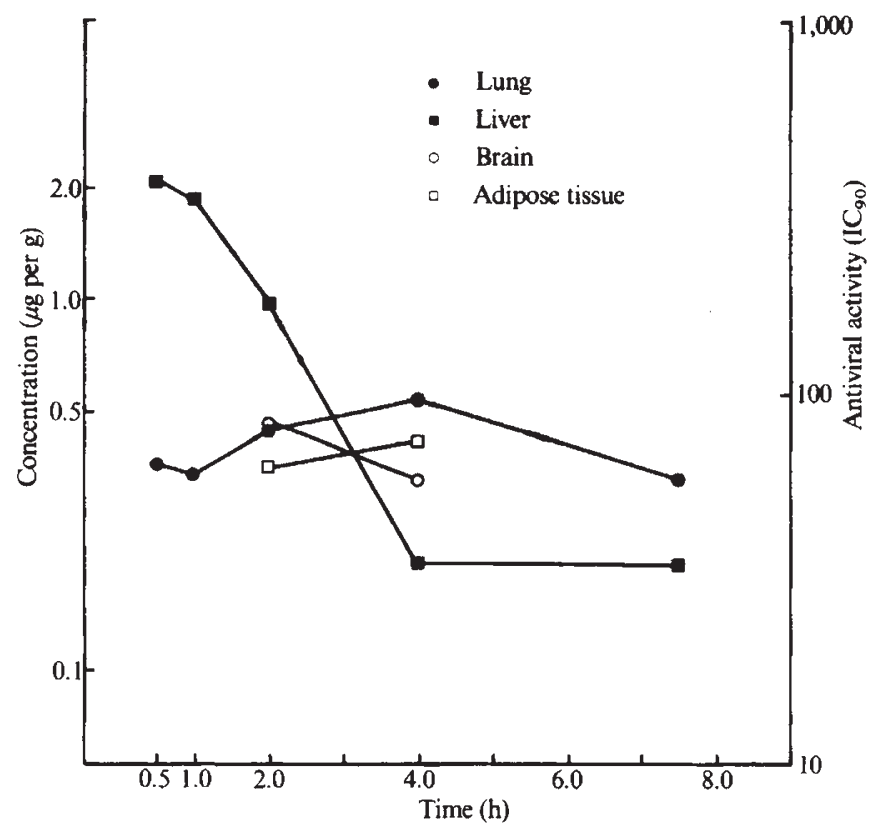

Fig. 1 Tissue concentrations of BW683C determined by gasliquid chromatography. Tissue homogenate $(1 \mathrm{ml})$ was mixed with $0.5 \mathrm{ml}$ ethylene glycol/water $/ 2 \mathrm{M}$ citric acid $(2: 2: 1)$ and $5 \mathrm{ml}$ hexane. The mixture was shaken for $30 \mathrm{~min}$ and centrifuged. The hexane layer was collected and mixed with $1 \mathrm{ml}$ of a mixture of ethylene glycol/1 $\mathrm{M} \mathrm{Na}_{2} \mathrm{CO}_{3}(1: 9)$, shaken again and centrifuged. The upper layer was collected, dried in a stream of $\mathrm{N}_{2}$ and the residue was dissolved in a small volume of toluene. 